\title{
THE ROLE OF THE EDUCATION SYSTEM IN SOLVING THE SKILLS MISMATCHES ON THE LABOR MARKET
}

\author{
Daniela Pașnicu \\ National Scientific Research Institute for Labor and Social Protection/ Spiru Haret University (Romania)
}

\begin{abstract}
The good functioning of the labor market depends to a large extent on the matching of skills and qualifications to the demands of employers. Significant and persistent mismatches over time, between training, skills, qualifications required and offered on the market can be costly for employers, workers and society in general. Countries are currently facing challenges such as technological and demographic changes that may contribute to deepening skills mismatch in the future.

The purpose of this study is to analyze the correspondence of qualifications in the labor market through the over-qualification rate and the evolution of the Beveridge curve and to contribute to a better understanding of the role of education and training system in solving the mismatches of qualifications in the labor market. The analyses are conducted in dynamics, over the period 2007-2017, at EU level and in two particular cases, Romania and the UK. The data underlying the "normative" measurement of the over-qualification rate, as well as the data used to draw the Beveridge curve, a widely scale used analysis tool in the literature to highlight the balance of the labor market, are derived from official EUROSTAT statistics. Analyses show that the over-qualification rate has increased over the considered period at the EU level and in the cases analyzed, especially among women. Furthermore, the results illustrate the need for additional efforts in order to achieve a balance on the labor market.
\end{abstract}

Keywords: Qualification mismatch, over-qualification, Beveridge curve, labor market.

\section{Introduction}

In the OECD Survey of Adult Skills (PIAAC) conducted in 24 OECD countries, around one third of workers were found to be over or under-qualified for the workplace, while a ratio of one to six indicates a mismatch between existing and required skills for their workplace (OECD, 2016). Most over-qualification data presented in Holmes and Mayhew (2015) suggest that over-qualification has increased over time. McGowan and Andrews (2015), which explored the link between labor market mismatch and labor productivity, based on PIAAC data (OECD Survey of Adult Skills) argue that over-qualification and quality mismatch is associated with lower labor productivity due to a less efficient allocation of resources. Grip, Loo, and Mayhew (2002) also argue that workers with sufficient and up-to-date qualifications are more productive and have greater potential to remain in employment. Therefore, it is necessary to improve the ability of economies to efficiently manage their existing stocks of human capital in the context of demographic aging and the decline in working-age population. Changes in supply and demand as a result of technological progress have been reflected in the incapacity of employers to fill vacancies with people with the necessary skills. Various sources have shown that four out of 10 EU employers have declared in 2013 that they have difficulties in finding the right recruitment skills (CEDEFOP 2018). Regarding the influence of technological advances on the world of work, it is estimated that until 2025 about $48 \%$ of all job opportunities in Europe will have to be filled by tertiary qualified persons (CEDEFOP, 2016) and the European Skills and Jobs Survey (ESJS) estimates that around $85 \%$ of all EU jobs require at least a basic level of digital competence (CEDEFOP 2015).

An effective education and training system should lead to lower levels of persistent non-correspondence between graduate skills and those required by the labor market. Higher education institutions need to ensure that they equip graduates with relevant and up-to-date skills (Europeen Commission 2016). Given that national imbalances can spread, regular studies are needed to assess and anticipate skill needs and potential surpluses and deficits, which are an important reference in the development of employment and education policies. 


\section{Objectives, indicators and tools used}

In this article, we aim to identify the similarities and differences between the EU, Romania and the United Kingdom (UK) as regards the correspondence of labor market qualifications and to understand the role of the education and training system in addressing the lack of correspondence of qualifications in the labor market. Romania was introduced to identify certain deficiencies, pluses or convergence compared to the EU or the UK, which can be an important knowledge base for the design of national policy instruments. The UK was choices for two reasons: 1. The OECD Survey of Adult Skills (PIAAC) concluded that England and Northern Ireland had one of the highest over-qualification rates (30\%), the second after Japan in the decreasing hierarchy and 2. to compare the situation on the Romanian labor market with an economically advanced EU Member State. The analysis of labor market dynamics of matching will be done between 2007 and 2017, using the over-qualified rate indicator and the Beveridge curve instrument, based on EUROSTAT data. These indicators were used as there are no commonly agreed indicators in the European Statistical System (SES) to measure the matching of qualifications.

The over-qualification rate refers to "vertical" skills mismatches, analyzing the discrepancies between education and occupations. The over-qualification rate was measured as the ratio of higher education graduates (ISCED 5-8) employed in non-tertiary occupations (ISCO 4-9 groups) and people with higher education.

The Beveridge Curve is a graphical representation that highlights the inversely proportional relationship between the vacancy rate and the unemployment rate. The efficiency of the functioning of the labor market is highlighted by this instrument as a result of the analysis of the curve movements, as follows: the movement along the curve is determined by the economic cyclicality; the movement of curve to the interior or exterior are determined by structural factors such as incompatibility between available jobs and professional training for the unemployed or the extent to which existing jobs are disappearing.

\section{Results}

\subsection{Over-qualification}

Over-qualification estimates the amount of skills, abilities and knowledge of an under-utilized workforce that could be better used, especially if there are employers who do not find highly qualified workers. At an individual level, over-qualified workers tend to earn more than others in the same job, which may indicate that their productivity is higher than that of workers whose competence corresponds to that required by the workplace. However, at the macro level, analyzing the degree of over-qualification of the workforce is important to ensure that its skills and knowledge are used to the full potential and where they are needed. The issue also has inter-generational implications, given the need to make full use of available human resources in the context of an aging population to ensure the sustainability of social security systems incorporating fairness and solidarity between generations in society (European Commission, 2017). Over-qualification is most often seen as the incapacity of employers to fill vacancies, despite the high unemployment rate. According to the results of the Cedefop survey (2014), about $25 \%$ of highly qualified people at EU level were over-qualified for their position.

The over-qualification rate in 2017, in the analyzed cases, are the following: $22.7 \%$, EU28; 23.3\%, AE19; $25.7 \%$ UK and $17.7 \%$ Ro. The share of people with higher education in jobs that do not require such training increased by $1.9 \%$ (EU28); 1.3\% (AE19), 2.1\% (UK) and 9\% (RO) in the analyzed range. Although Romania has the lowest value for this indicator, it recorded the highest growth.

Figure 1. Over-qualification rate during 2007-2017 (\%).

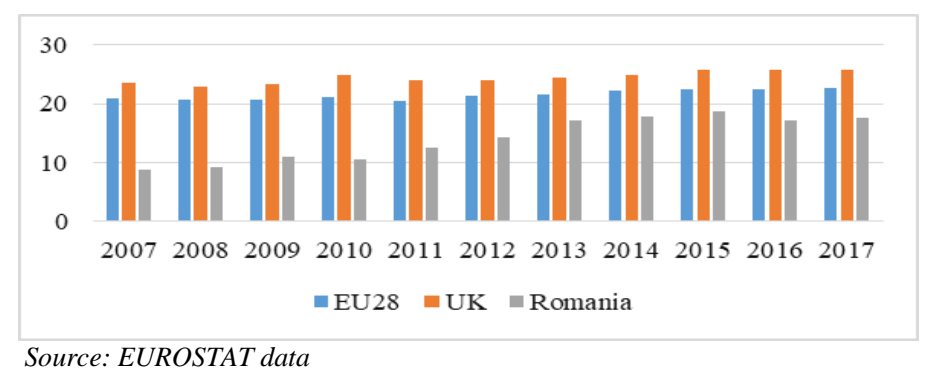

\subsection{Beveridge curve}

In the EU28, since the end of 2013, a movement along the curve was again visible, reflecting economic expansion with the rise in vacancies and declining unemployment. In 2017, especially in the second semester, vacancies increased sharply and more than the fall in unemployment, suggesting that 
skills mismatches could prevent an improvement in the unemployment rate. This would mean that the unemployment rate is approaching its structural rate, which is the rate that could not be further reduced by economic growth. In Romania, 2010-2013 period is characterized by specific elements of the economic crisis, namely the rate of low jobs and a high unemployment rate. The economic recovery starting in 2013 is also on the right-hand side of the recession curve, as in the case of the EU28, but from 2016 the curve moves to the left, indicating a stagnation in the vacancy rate, amid a reduction in the unemployment rate. The low unemployment rate, combined with a general fall in the labor force and persistent shortages in qualified personnel, has led to rigid conditions on the national labor market. In the Beveridge curve for the UK, there is a decline in unemployment coupled with the rise in vacancies, revealing a strong economic recovery.

Figure 2. EU28, 2007-2018

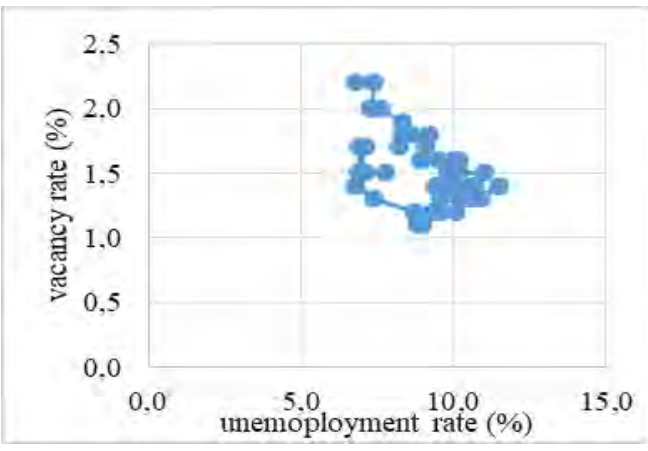

Figure 3. Romania, 2007-2018

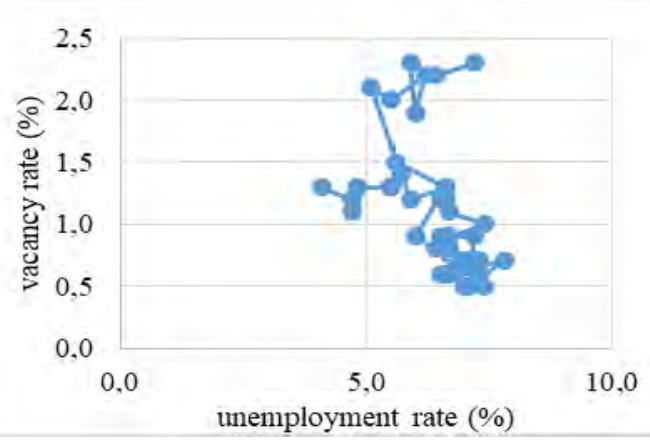

Source: EUROSTAT dato

\section{Conclusions}

The lack of qualified staff due to aging and falling work force and labor market miss-matching have a negative effect on competitiveness. The fall in unemployment rate close to structural value and the growth / stagnation of vacancy rates indicate the need to increase labor market participation, including of the low-skilled and other vulnerable groups. Also, the increase in the over-qualification rate over the last period illustrates inefficient use of the workforce and therefore lower productivity. Over-qualification often hides the heterogeneity of qualifications, so it cannot be the result of a quantitative mismatch between the number of tertiary graduates and the number of graduate job, but rather a skill issue that new employees do not have despite having a degree tertiary. The immediate response of the education system to changes in the demand for qualifications is also crucial, especially in the context of technological progress and innovation. Adult learning and training should address both obsolescence qualifications, continuous training for top-notch qualifications, and new skill requirements due to technological change.

\section{References}

Cedefop (2015) Skills, qualifications and jobs in the EU: the making of a perfect match?, Cedefop reference series No 3072, http://dx.doi.org/10.2801/606129

Cedefop (2016). Future skill needs in Europe: critical labour force trends. Luxembourg: Publications Office. Cedefop research paper; No 59. http://dx.doi.org/ 10.2801/56396.

Cedefop (2018). Insights into skill shortages and skill mismatch: learning from Cedefop's European skills and jobs survey. Luxembourg: Publications Office. Cedefop reference series; No 106. http://data.europa.eu/doi/10.2801/645011

European Commission (2016) A new skills agenda for Europe, working together to strengthen human capital, employability and competitiveness, Brussels, 10.6.2016 COM (2016) 381 final

European Commission (2017), Employment and Social Developments in Europe, Annual Review 2017, http://data.europa.eu/doi/10.2767/144714

Grip, A., Loo, J. and Mathew, K. (2002), The Economics of Skills Obsolescence: Theoretical Innovations and Empirical Applications, Emerald Publishing Limmited, JAI Press Inc, Bingley, US

Holmes, C and Mayhew, K. (2015), Over-qualification and skills mismatch in the graduate labour market, Policy report, London, CIPD

McGowan, M., A and Andrews, D. (2015) Labour Market Mismatch and Labour Productivity: Evidence from Piaac Data, London, Paris, OECD no. 1209

OECD (2016), Skills Matter: Further Results from the Survey of Adult Skills, OECD Skills Studies, OECD Publishing, Paris. http://dx.doi.org/10.1787/9789264258051-en. 